\title{
ALTERAÇÕES ANATÔMICAS EM ESTACAS DE SERINGUEIRA (Hevea brasiliensis clone RRIM 600) EM RESPOSTA A DIFERENTES TÉCNICAS DE INDUÇÃO AO ENRAIZAMENTO
}

\author{
M.J.S. MEDRADO'; ${ }^{1}$ B. APPEZZATO-DA-GLÓRIA ${ }^{2}$; J.D. COSTA $^{3}$ \\ 'CNPF/EMBRAPA, C.P. 319, CEP: 83405-990, Colombo,PR \\ ${ }^{2}$ Departamento de Botânica-ESALQ/USP, C.P. 9, CEP: 13418-900, Piracicaba,SP \\ ${ }^{3}$ Departamento de Agricultura-ESALQ/USP, C.P. 9, CEP: 13418-900, Piracicaba,SP
}

\begin{abstract}
RESUMO: Clones de seringueira (Hevea spp ) são enxertados sobre porta-enxertos oriundos de sementes de ascendência desconhecida e por isto não exteriorizam todo seu potencial genético de produção de látex. A superação desta dificuldade pode ser obtida com o enraizamento de estacas clonais. Todavia, a seringueira é considerada em seu estágio adulto como uma planta de dificil enraizamento. Estas plantas possuem na base do caule um cilindro quase contínuo de tecidos lignificados, que juntamente com barreiras químicas podem dificultar o enraizamento. Atualmente, algumas plantas de dificil enraizamento, têm enraizado com a ajuda de um conjunto de técnicas modernas como estiolamento total ou localizado e estrangulamento. Este trabalho, procurou caracterizar as modificações que ocorrem em estacas clonais de seringueira submetidas aquele conjunto de técnicas. Pode-se concluir que o estrangulamento da base de estacas do clone RRMM 600, assim como sua utilização em conjunto com os dois tipos de estiolamento, promoveu alterações na atividade do câmbio vascular que produxiu maior número de células parenquimáticas no floema, resultando na descontinuidade da bainha de fibras perivasculares, 0 que representa um indício para 0 favorecimento ao enraizamento das estacas.
\end{abstract}

Descritores: Hevea brasiliensis, estacas, raizes adventícias, anatomia

\section{ANATOMICAL CHANGES IN RUBBER TREE CUTTINGS (Hevea brasiliensis CLONE RRIM (00) IN RESPONSE TO DIFFERENT ROOTING TECHNIQUES}

\begin{abstract}
Clones of Hevea spp are presently grafted on seedlings, because no economic method of producing clonal rootstocks by vegetative means or clonal cuttings has so far been discovered. Because of this, Hevea clones do not exteriorize their maximum genetic potential for latex production. The rooting of clonal cuttings overcomes this problem. However, Hevea is considered a plant with very poor capacity of rooting, in its mature phase. Plants have at the stem base an almost continuous cylinder of lignified tissues, which along with chemical barriers can difficult rooting. At present, rooting problems in some plant species may be overcome by a combination of new techniques as it is the case of total or local etiolation and girdling. This work has the aim to characterize the modifications occurred in clonal cuttings of Hevea when subjected to the above mentioned techniques, alone or combined. It was possible to conclude that the girdling of the cutting base from the RRIM 600 clone, as well as its utilization in combination with the other two types of etiolation, promoted drastic alterations in the sheath, as compared to the control. Moreover, girdling promoted the activity of the vascular cambio, which produced a greater number of parenquimatous cells in the phloem, resulting in a discontinuity, of the perivascular fibers sheath. Other alterations elapsed of the girdling were: the division of parenquimatous cells around of the sheath forming meristematic rings and a greater number of lenticells in comparison to the control, which can favor the rooting of the cuttings.
\end{abstract}

Key Words: Hevea brasiliensis, cutting, adventitious rooting, anatomy

\section{INTRODUÇÃO}

Clones de seringueira normalmente são enxertados sobre porta-enxertos oriundos de sementes de ascendência desconhecida. Este méto- do de propagação tem a desvantagem de impedir a exteriorização de todo o potencial produtivo dos clones, em virtude da incompatibilidade que pode ocorrer entre enxerto e porta-enxerto. Para superar tal problema, vários estudos têm sido conduzidos 
sobre a possibilidade da propagação da seringueira por estaquia (MUZIK 1953; LANE, 1954; WERSUM, 1955; MUZIK \& CRUZADO, 1956 e 1958; MENDES 1959; TINLEY \& GARNER, 1960 e TINLEY, 1961). Destes autores, apenas TINLEY \& GARNER (1960) mostraram ser viável a produção de estacas enraizadas de clones de seringueira em escala comercial.

Plantas jovens, freqüentemente diferem morfológica e fisiologicamente de plantas adultas da mesma espécie. Algumas vezes, brotações adventícias ou "juvenis" de plantas velhas, podem ser usadas para propagação enquanto que, estacas de ramos de plantas maduras quase não enraízam (STOUTMEYER, 1937; DERMEN, 1948). O problema de juvenilidade é de particular interesse na propagação da seringueira, onde estacas de plantas jovens regeneram raízes facilmente, porém estacas de árvores velhas são de difícil enraizamento (MUZIK 1953, MUZIK \& CRUZADO, 1956 e 1958). Algumas plantas tropicais de difícil enraizamento como a seringueira, possuem na base do caule com um ano de idade, um cilindro quase contínuo de elementos lignificados (BEAKBANE, 1961). Esta autora afirma que as diferenças no grau de esclerificação entre clones, apesar de relativamente estáveis, podem ser afetadas por efeitos ambientais como sombreamento e estiolamento parcial.

SACHS et al. (1964) questionam a presença de uma barreira física como impedimento ao enraizamento. Os autores mostraram espécies que enraizam mesmo apresentando um anel de fibras ao redor do floema. GOODIN (1965) concorda com BEAKBANE (1961) que é muito difícil explicar o problema do enraizamento estritamente com base em uma barreira mecânica. Segundo este autor, existem plantas de difícil enraizamento como Pfitosporum, que não apresentam um anel de es-clerênquima perivascular. SACHS et al. (1964) também mostraram que não houve relação entre a densidade e continuidade do anel esclerenquimático e a facilidade para enraizar em estacas de sete variedades de oliveiras. De acordo com GOODIN (1965), deve haver também um envolvimento químico. A literatura sugere que há uma resposta química ao enraizamento, porém é provável que a diminuição na proporção entre tecidos esclerenquimatosos e parenquimatosos promova condições para a formação de primórdios radiculares. Além disso, a quebra da barreira de esclerênquima se não é o principal fator para o enraizamento, deve facilitar o desenvolvimento de primórdios.

Atualmente, algumas plantas de difícil enraizamento têm enraizado com a ajuda de um conjunto de técnicas modernas como estiolamento total ou localizado e estrangulamento (ELIASSON \& BRUNES, 1980; VEERARAGAVATHATHAM et al., 1985; NAGESWARA RAO et al., 1988). Este trabalho, tem por objetivo analisar as alterações anatômicas provocadas pelo estrangulamento, estiolamento da base da estaca e estiolamento total da planta matriz, sob a ótica da facilidade de enraizamento.

\section{MATERIAIS E MÉTODOS}

As estacas foram preparadas cm plantas matrizes de clone RRIM 600, de um jardim clonal, do Departamento de Agricultura da Escola Superior de Agricultura "Luiz de Queiroz", em Piracicaba, Estado de São Paulo. Esse jardim clonal tinha três anos de idade e sobre ele, em anos anteriores, já haviam sido efetuadas duas podas para coleta de hastes.

As práticas utilizadas com a finalidade de facilitar o enraizamento das estacas, e das quais se originaram os tratamentos foram: a) Estiolamento total: consistiu do isolamento total, por $\mathbf{3 0}$ dias, de parte do jardim clonal, através da confecção de uma casa com madeira e lona plástica preta, de cerca de $2 \mathrm{~m}$ de altura; b) Estiolamento localizado: foi obtido enrolando-se, por 30 dias, a base de cada ramo, com uma fita plástica preta de $5,0 \mathrm{~cm}$ de largura por cerca de $10 \mathrm{~cm}$ de comprimento, do mesmo material usado para a confecção da casa quando do estiolamento total; $e$ c) Estrangulamento: foi feito deixando-se amarrada, por 30 dias, a base de cada ramo com um fio de cobre $n^{\circ} 21$; no caso dos ramos submetidos a estiolamento localizado o fio de cobre foi amarrado imediatamente abaixo da fita plástica.

Tanto o estiolamento localizado quanto o estrangulamento só tiveram início após o término do estiolamento total, para que pudessem ser comparados com suas combinações ao estiolamento total.

Os tratamentos consistiram de: (T0) controle; (T1) estacas submetidas a estiolamento total(ET) + estiolamento localizado (EL) + estrangulamento (E); (T2) estacas submetidas a estrangulamento (E) + estiolamento total (ET); 
(T3) estacas submetidas a estiolamento total (ET) + estiolamento localizado (EL); (T4) estacas estranguladas (E); (T5) estacas submetidas a estrangulamento (E) + estiolamento localizado; (T6) estacas submetidas a estiolamento total (ET); (T7) estacas submetidas a estiolamento localizado (EL).

Após a aplicação de cada tratamento foram extraídos os ramos que cortados a $20 \mathrm{~cm}$ de sua base deram origem a estacas, das quais removeu-se a parte basal $(5,0 \mathrm{~cm})$ que foi fixada em FAA 50 (SASS, 1951). Os cortes feitos no micrótomo de deslize, foram corados com verde iodo e vermelho-congo segundo DOP \& GAUTIÉ (1928). Foram tiradas fotomicrografias do material preparado em lâminas.

\section{RESULTADOS E DISCUSSÃO}

A base da estaca normal do clone RRIM 600 , apresenta uma bainha quase contínua de fibras perivasculares que pode dificultar a passagem de primórdios radiculares (Figuras 1A e 1B, setas). Esta barreira, apesar de não ser o único fator de impedimento ao enraizamento (SACHS et al., 1964, GOODIN 1965 e HARTMANN et al, 1990), pode se somar às barreiras químicas que porventura estejam interferindo na capacidade de enraizamento do clone.

O estrangulamento das brotações, juntamente com o estiolamento total e localizado, ou seja, o tratamento completo (ET+EL+E) promoveu alterações na atividade do câmbio vascular, que passou a produzir um número proporcionalmente maior de células parenquimáticas no floema (Figura 2A). Tal proliferação celular já comentada por STOLZ \& HESS (1965), parece ser um dos fatores de rompimento do anel de fibras mencionado anteriormente (Figura 2B, setas). Deve-se ressaltar que o tecido parenquimático, por apresentar a alta capacidade de desdiferenciação celular, pode possibilitar a organização de novos primórdios. $E$, de acordo com SACHS et al. (1964), DAVIES $e t$ al. (1982) e WHITE \& LOVELL (1984), as grandes diferenças encontradas na capacidade dos tecidos situados por dentro do anel esclerenquimático, na formação de primórdios radiculares parece ser mais importante do que a restrição mecânica à emergência das raízes.

Nos demais tratamentos com estrangulamento $(E+E T, E+E L$ e $E)$, além da alteração na atividade cambial, as células parenquimáticas situadas ao redor dos grupos de fibras, isolados pela atividade cambial, dividem-se periclinalmente formando um anel meristemático (Figuras 3A e 3B, retas). Tal formação também foi verificada em estacas de ramos aéreos de Mandevilla (APPEZZATO-DA-GLÓRIA, 1993). Segundo o autor, as raízes adventícias emergem após o afastamento dos cordões de fibras, resultante da atividade meristemática. Porém, algumas espécies continuam a ter problemas no enraizamento, mesmo que ocorra quebra na continuidade do anel esclerenquimático, por atividade meristemática (HARTMANN et al., 1990).

Os anéis meristemáticos geralmente encontram-se opostos às lenticelas (Figura 3A, seta) que aparecem em maior número comparado ao controle. Vários autores têm associado a presença das lenticelas aos sítios de iniciação de raízes adventícias de tal forma que as raízes, freqüente-mente, podem emergir via lenticela (LOVELL \& WHITE, 1986 e APPEZZATO-DAGLÓRIA, 1993).

\section{CONCLUSÕES}

- Os tratamentos sem estrangulamento, ou seja ET + EL e EL não promoveram alterações visíveis na bainha esclerenquimática, que permaneceu como no controle. Por sua vez, os tratamentos com estrangulamento (ET + EL + E; ET + E; EL + $\mathrm{E} \mathrm{e}$ E) apresentaram drásticas alterações na bainha, quando comparados ao controle.

- As técnicas envolvendo estrangulamento promoveram alterações na atividade do câmbio vascular, que passou a produzir um número proporcionalmente maior de parênquima floemático. Tal proliferação resultou no afastamento das fibras situadas no anel.

- Outras alterações decorrentes do estrangulamento foram a divisão das células parenquimáticas situadas ao redor das fibras com a formação de anéis meristemáticos e a presença de um número maior de lenticelas quando comparado ao controle.

- As alterações estruturais verificadas neste estudo são similares às descritas para outras espécies recalcitrantes que formaram raízes adventicias $\mathrm{em}$ resposta às técnicas de enraizamento. 

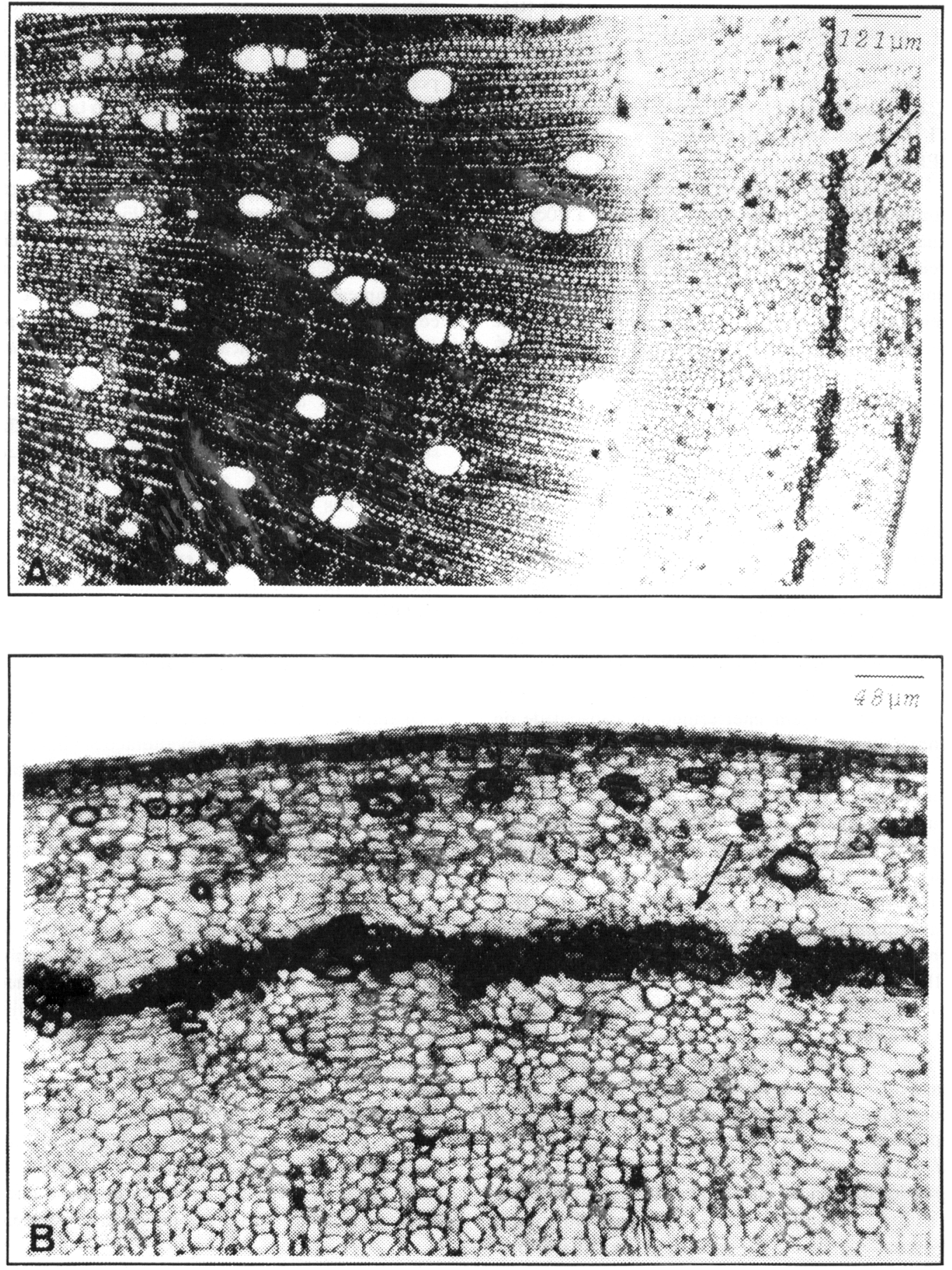

Figura 1 - Cortes transversais da base de estacas de plantas matrizes de seringueira clone RRIM 600 . (A) Visão geral. (B) Deta-lhe do anel esclerenquimático (seta) indicado em A.

Sci. agric., Piracicaba, 52(1):89-95, jan./abr. 1995 

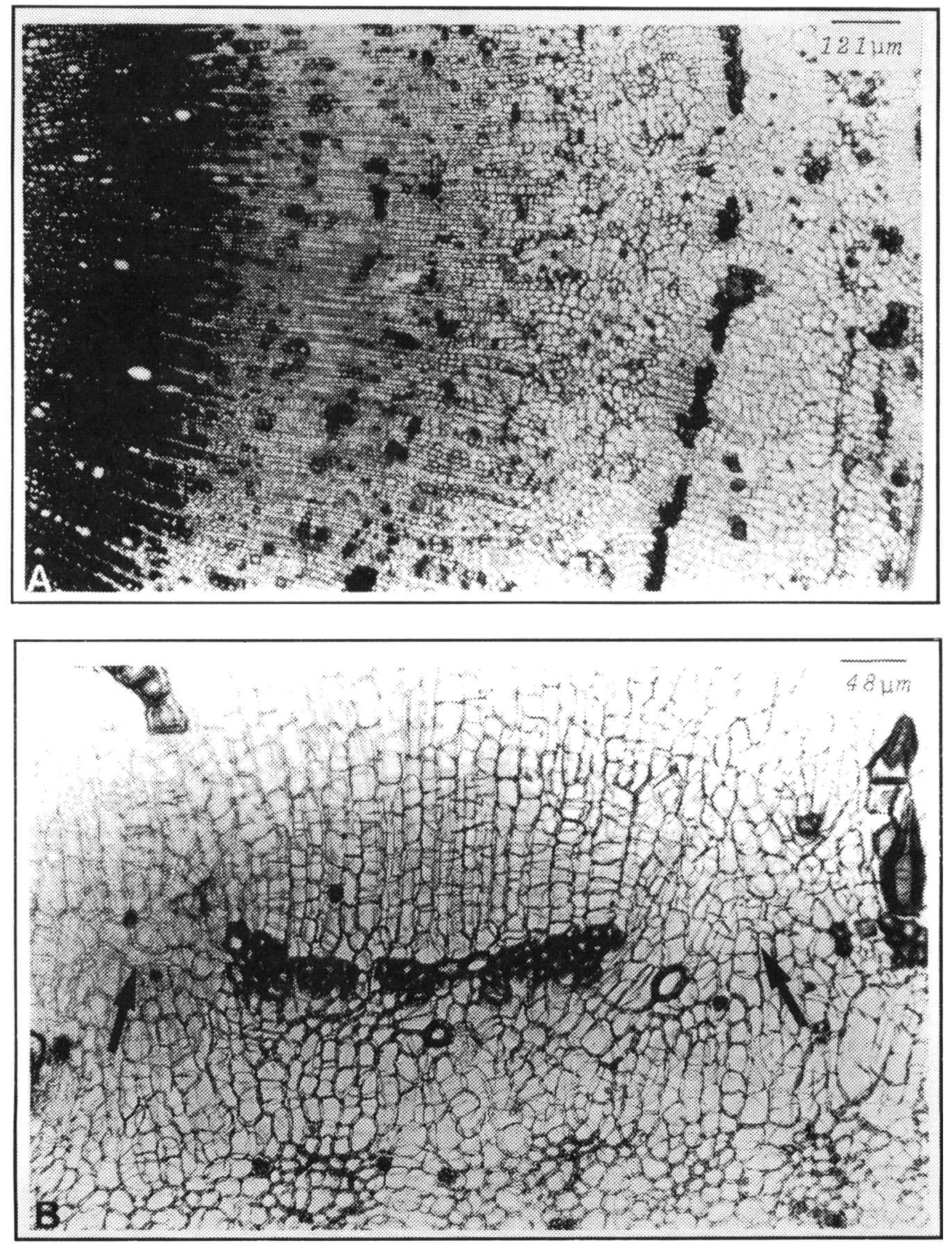

Figura 2 - Cortes transversais da base de estacas de plantas matrizes de seringueira clone RRIM 600 submetidas ao estrangulamento. (A) Visão geral mostrando alterações estruturais; nota-se a quantidade maior de parênquima floemático. (B) Detalhe da separação das fibras resultante da atividade meristemática (setas). 

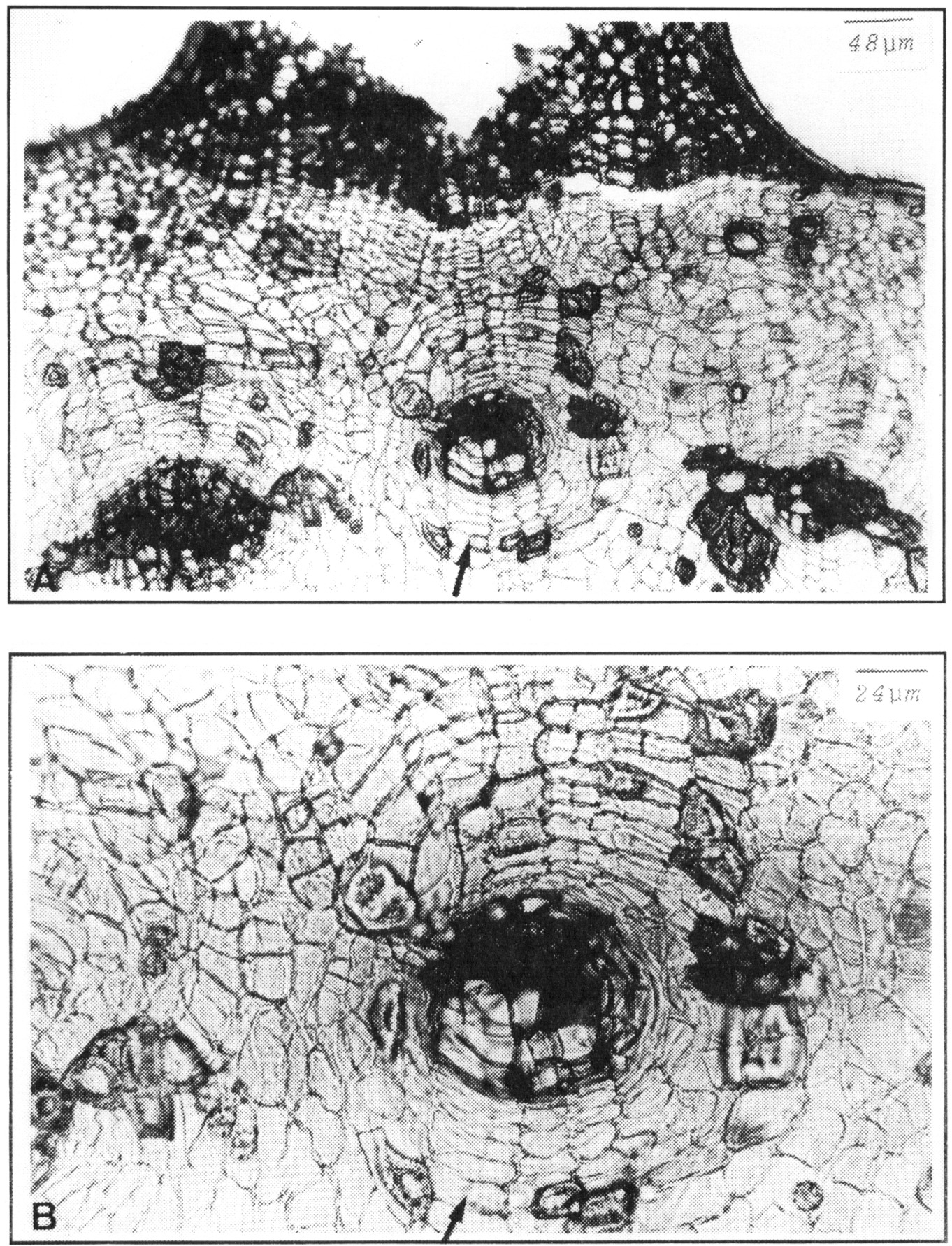

Figura 3 - (A) Lenticela observada na base de estaca submetida ao tratamento completo (ET + EL + E). (B) Detalhe da região indicada em A mostrando um dos cordões de fibras envolvido por um anel meristemático (seta). 


\section{LITERATURA CITADA}

APPEZZATO-DA-GLÓRIA, B. Caracteres anatômicos e ultraestruturais dos órgãos vegetativos de Mandevilla illustris (Vell.) Woodson e $M$. velutina (Mart. ex Stadelm.) Woodson- Apocynaceae. São Paulo, 1993. 122p. Tese (Doutorado) - Instituto de Biociências, Universidade de São Paulo.

BEAKBANE, A.B. Structure of the plant stem in relation to adventitious rooting. Nature, London, v.192, n.4806, p.954-955, 1961.

DAVIES JR., F.T.; LACERATE, JOE.; JOINER, JAN. Initiation and development of roots in juvenile and mature leaf bud cuttings of Ficus pumila L. American Journal of Botany, Columbus, v.69, n.5, p.804-811, 1982.

DERMEN, H. Chimera apple sports. Journal of Heredity, New Jersey, v.39, p.235-242, 1948.

DOP, P.; GAUTIÉ, A. Manual de technique botanique. 2.ed. Paris: J. Lamarre XXII, 1928. 594p.

ELIASSON, L.; BRUNES, L. Light effects on root formation in aspen and willow cuttings. Physiologia Plantarum, Munksgaard, v.48, p.261-265, 1980.

GOODIN, J.R. Anatomical changes associated with juvenile-to-mature growth phase transition in Hedera. Nature, London, v.208, n.5009, p.504-505, 1965.

HARTMANN, H.T.; KESTER, D.E.; DAVIES JR., F.T. Plant propagation: principles and practices. 5.ed. Englewood Cliffs: Regents Prentice Hall, 1990. $647 p$.

LANE, E.V. The early days of rubber in Ceylon. Indian Rubber Journal, New Delhi, v.127, n.10, p.4, 1954.

LOVELL, P.H.; WHITE, J. Anatomical changes during adventitious root formation. In: JACKSON, M.B., (Ed). New root formation in plants and cuttings. Lancaster: Martinus Nijhoff, 1986. cap.4, p.111-140.

MENDES, L.O.T. A multiplicação da seringueira (Hevea brasiliensis Muell. Arg.) por meio de estacas. Bragantia, Campinas, v.18, n.17, p.245-274, 1959.

MUZIK, T.J. Growth and regeneration in Hevea seedlings. Science, Washington. v.117, p.555-556, 1953.

MUZIK, T.J.; CRUZADO, H.J. Formation and rooting of adventitious shoots in Hevea brasiliensis. American Journal of Botany, Columbus, v.43, n.7, p.503-508, 1956.
MUZIK, T.J.; CRUZADO, H.J. Transmission of juvenile rooting ability from seedlings to adults of Hevea brasiliensis. Nature, London, v.181, n.4618, p.1288, 1958.

NAGESWARA RAO, M.B.; SATYANARAYA-NA, G.; SHIV RAJ, A.; GNANA KUMARJ, N.; PADMANABHAM, V. Influence of post-ringing period on cofactor activity and total phenol content in ringed shoot cuttings of cashew (Anacardium occidentale L.). Tropical Agriculture, Trinidad, v.65, n.4, p.370-372, 1988 .

SACHS, R.M.; LORETI, F.; DE BIE, J. Plant rooting studies indicate sclerenchyma tissue is not restricting factor. California Agriculture, Oakland, v.18, n.9, p.4-5, 1964

SASS, J.E. Botanical microtechnique. Iowa: Iowa State College Press, 1951. 228p.

STOLTZ, L.P.; HESS, C.E. The effect of girdling upon root initiation: carbohydrates and amino acids. Proceedings of the American Society for Horticultural Science, St. Joseph, v.89, p.744-743, 1965.

STOUTMEYER. V.T. Regeneration in various types of apple wood. Iowa Agricultural Experimental Station Research Bulletin, Ames, v.220, p.309-352, 1937.

TINLEY, G.M. Effects of ferric dimethylditio-carbamate on the rooting of cuttings of Hevea brasiliensis. Nature, London, v.191, n.4794, p.1217-1218, 1961.

TINLEY, G.M.; GARNER, R.J. Developments in the propagation of clones of Hevea brasiliensis by cuttings. Nature, London, v.186, n.4722, p.407-408, 1960.

VEERARAGAVATHATHAM, D.; MADHAVA RAO, V.N.; SHANMUGAVELU, K.G. Effect of etiolation in rooting of stem cuttings jasminae. Indian Joumal of Horticulture, Bangalore, v.42, n.3/4, p.287-289, 1985.

WHITE, J.; LOVELL, P.H. The anatomy of root initiation in cuttings of Griselinia littoralis and Griselinia lucida. Annals of Botany, London, v.54, p.7-20, 1984.

WIERSUM, L.K. Observations on the rooting of Hevea cuttings. Archives of Rubber Cultivation, Djakarta, v.32, n.2, p.213-243, 1955.

Entregue para publicação em 10.04.94

Aceito para publicação em 10.11 .94 